\title{
Chiari Formation: Atlantoaxial Instability is the Cause
}

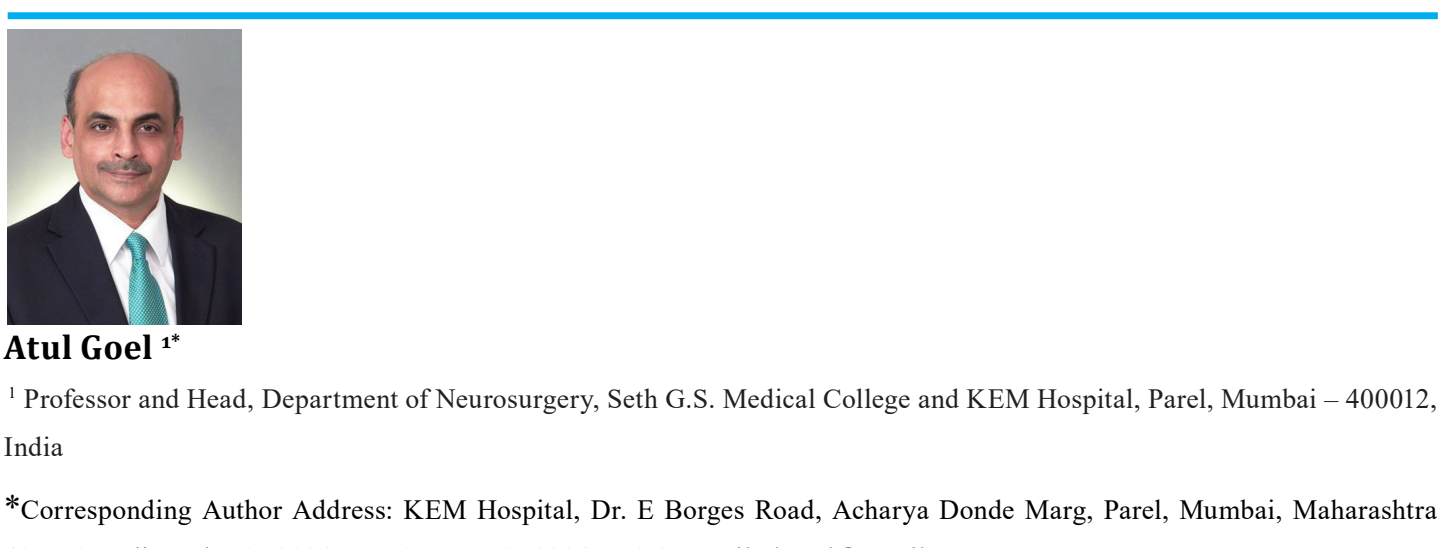

400012, India. Tel: +91-2224107000. Fax:+91-2224155678. Email: dratul@gmail.com

Article Type: Editorial Received: September 2, 2017, Last Revised: September 5, 2017, Accepted: September 10, 2017, Published: September 28, 2017

Please cite this paper as: Goel A. Chiari Formation: Atlantoaxial Instability is the Cause. Iran J Neurosurg. 2017;3(2):36-38

The entity of Chiari formation was described by Hans Chiari in 1891 [1,2]. Since then the subject has been evaluated elaborately by a number of authors. However, it may only be correct to state that confusion in the understanding of pathogenesis and the nature of anomaly, significance of associated abnormal soft tissue and bone anomalies and more importantly the treatment of the entity has not been resolved. The number of described treatment patterns are a testimony to the inadequacy of the understanding. The general consensus is that uncal herniation and tonsillar herniation are both similar in their pathogenesis wherein the part of the temporal brain or the cerebellum are pushed out of their compartment through a hiatus or hole into the other body compartment. In the process of herniation, there is congestion of space and compromise of the neural structures in the vicinity that leads to neurological symptoms or deficits. The factor that causes the push in case of Chiari malformation is unclear. However, the presence of an increased volume of cerebellar mass, a smaller volume of the posterior cranial fossa bone compartment or a combination of both these factors could be the possible cause.

The general understanding is that the addition of the tonsillar volume in the foramen magnum limits the space for the neural structures that are compressed and results in related symptoms. Foramen magnum decompression is an established and a gold standard form of treatment. The operation is aimed at increasing the volume of foramen magnum so that the neural structures can function freely. The technique of performing foramen magnum decompression has wide variations. The need for doing $\mathrm{C} 1$ laminectomy, $\mathrm{C} 2$ laminectomy, opening the dura, dural grafting, reconstruction of the bone, arachnoid dissection around the tonsils or tonsillar resection is still being debated. It may only be correct to infer that the last word regarding the nature of treatment and the method of its execution has not yet said.

Chiari formation is frequently associated with musculoskeletal abnormalities of basilar invagination or neural abnormalities of syringomyelia [3,4]. More often, Chiari formation is not associated with any bone or soft tissue anomaly. It is difficult to comprehend ifChiari formation is associated with these abnormalities which are different forms or faces of the same disease.

In the year 2014, we introduced a concept that Chiari formation is neither a primary problem nor a related congenital malformation or embryonic dysgenesis $[5,6]$. It was identified that Chiari formation is a secondary and a natural protective response to atlantoaxial instability. Essentially, it means that Chiari formation is a protective natural process and is a result of manifest or potential atlantoaxial 
instability. Chiari is a formation wherein the tonsils are positioned in the craniovertebral junction as a protective cushion or an airbag designed to prevent compression of critical neural structures from getting pinched or compressed between bones [5]. Chiari is a formation and not a malformation [7]. It is a result of remarkable ability of nature to protect the human body in the face of instability of the most crucial atlantoaxial joint and from the most dangerous bone odontoid process.

Essentially, it means that Chiari malformation indicates the presence of atlantoaxial instability. It also means that atlantoaxial stabilization is the treatment in such cases. It was identified that foramen magnum decompression may be counterproductive surgical procedure. We had earlier suggested that improvement in the clinical condition following foramen magnum decompression is like relief to the person after the full air bag is deflated following a car accident. Although there is an immediate relief from symptoms, the person loses his/her airbag, and the whole process is counter-effective in the long run. It was also speculated that the pain and stiffness of the suboccipital muscles following foramen magnum decompression may, by itself, result in stabilization of the neck and the atlantoaxial joint and improvement in the symptoms.

Atlantoaxial joint is the most mobile joint of the body. Its flat and round articular surfaces allow unrestricted circumferential movements. Whilst the joint structure allows wide-ranging movements, it is subject to an exaggerated risk of instability. For several decades, analysis of abnormal alteration of atlantodental interval on dynamic radiographs with the head in flexion and in extension has been the sole parameter of determining atlantoaxial instability. Indentation of the neural structures by the tip of the odontoid process was another indicator of presence of atlantoaxial instability. Analysis of the facetal alignment on neutral head position and assessment of bones during surgery by manual manipulation are novel ways to evaluate atlantoaxial instability [8]. In type 1 instability, the facet of atlas is dislocated anterior to the facet of axis. In this type of dislocation, the atlantodental interval is increased, and there is some evidence of dural and neural compression by the odontoid process. Such a type of atlantoaxial instability is more often associated with acute neurological symptoms and only infrequently with a chronic neurological issue like that of Chiari formation and syringomyelia. Type 2 instability happens when the facet of atlas is dislocated posterior to the facet of axis. In such a dislocation, the atlantodental interval may not be affected or abnormally altered. Type 3 instability takes place when the facets of atlas and axis are in alignment. In such cases, the diagnosis of atlantoaxial instability is made by the high degree of clinical suspicion, understanding of the subject and operative experiences. Type 2 and 3 atlantoaxial instability, wherein there is no compression of either the dural tube or the neural structures that are labelled as central or axial atlantoaxial instability. Such types of instability are usually associated with more chronic forms of atlantoaxial instability. In cases with Chiari formation, central or axial instability is a more common finding [9].

Chiari formation is frequently associated with a number of musculoskeletal and neural abnormalities. Basilar invagination is a frequent accompaniment. Short head, torticollis, Klippel-Feil bone abnormalities, platybasia, assimilation of atlas, C2-3 fusion, and bifid posterior arch of atlas are hallmarks of basilar invagination. In the year 2009, we speculated that all these bone abnormalities associated with basilar invagination are secondary and protective formations to counter, stall, and delay the effects of atlantoaxial instability, from the potential injury to the neural structures by the odontoid process [10]. It was identified that atlantoaxial fixation results in postoperative reversal of all musculoskeletal abnormalities [10]. This fact suggests that apart from atlantoaxial instability, there is no other pathological event, and the secondary musculoskeletal abnormalities are protective responses and are not embryonic disorders as has been widely understood. All these secondary events are reversible following atlantoaxial fixation [11,12].

Chiari formation and syringomyelia are both neural manifestation of atlantoaxial instability that may be manifest or may only 
be potential. Such instability is recognised by nature, before it can be radiologically demonstrated or confirmed. The very fact that the symptoms improve in the immediate postoperative period and the recovery process is sustained following atlantoaxial stabilization without any kind of foramen magnum decompression confirms this impression. Moreover, there is a potential for tonsillar herniation to regress and syrinx cavity to reduce or entirely disappear following atlantoaxial fixation. Improvement in clinical symptoms in patients who have failed foramen magnum decompression is also suggestive of the fact that atlantoaxial instability is the cause, and Chiari formation and syringomyelia are the protective natural responses.

We identified that in cases with Chiari formation there is excessive cerebrospinal fluid (CSF) content within the spinal cord (syringomyelia) or outside the spinal cord (external syringomyelia) [13-15]. Similarly, there is excessive or more than normal amount of CSF within the brainstem (syringobulbia) or around the brainstem (external syringobulbia). The posterior cranial fossa having excessive amount of CSF is not tight. The superior vermis is atrophied along with other parts of the cerebellum [16]. However, the tonsils by themselves are 'solid' and do not have any sulci or suggestion of excessive water content.

Basilar invagination is commonly associated with short neck and torticollis. It is also associated with shortening of clivus and platybasia. Both these events make the head 'short' [17]. Our studies conclude that there is anteroposterior elongation of the posterior cranial fossa and vertical reduction in its size. Similarly, there is anteroposterior enlargement of spinal canal dimension and vertical reduction in the height of entire spinal column, or there is short spine and short body height. The spinal canal size increases, but the neural girth dimensions decrease. The result is that the extraneural space is occupied by CSF. The CSF may be inside the cord (syringomyelia) and may be outside the cord (external syringomyelia) giving an appearance of atrophy of the cord. The increase in transverse dimension and decrease in vertical dimension of the spine and increase in the water content of the posterior cranial fossa and spinal canal are probably attempts of nature to reduce the entire length of the spinal cord, make it float in an excessive pool of CSF and limit the stretch of the cord on the odontoid process.

The extent of basilar invagination and angulation of the odontoid process are the determinants of presence of external or internal syrinx [15]. All these manoeuvres are unique natural games designed to stall, limit or delay the neurological deficits.

\section{References}

1. Chiari H. Ueber Veranderungen des Kleinhirns, des Pons und der Medulla oblongata infolge von kongenitaler Hydrocephalie des Grosshirns. Denkschr Akad Wiss, Wien. 1895; 63:71-116.

2. Chiari H: Ueber Verinderungen des Kleinhirns infolge von Hydrocephalie des Grosshirns. Deulsch Med Wschr. 1981; 17(42):1172-5.

3. Goel A, Bhatjiwale M, Desai K. Basilar invagination: a study based on 190 surgically treated patients. J Neurosurg. 1998; 88(6):962-8.

4. Goel A. Treatment of basilar invagination by atlantoaxial joint distraction and direct lateral mass fixation. J Neurosurg Spine 2004;1:281-6.

5. Goel A. Is Chiari malformation nature's protective "airbag"? Is its presence diagnostic of atlantoaxial instability? J Craniovertebr Junction Spine. 2014; 5(3):107-9.

6. Goel A. Is atlantoaxial instability the cause of Chiari malformation? Outcome analysis of 65 patients treated by atlantoaxial fixation. J Neurosurg Spine. 2015; 22(2):116-27.

7. Goel A. Is Chiari a "formation" or a "malformation". J Craniovertebr Junction Spine. 2017; 8 (1): 1-2.

8. Goel A: Goel's classification of atlantoaxial "facetal" dislocation. J Craniovertbr Junction Spine. 2014; 5 (1): 15-9.

9. Goel A. Central or axial atlantoaxial instability: Expanding understanding of craniovertebral junction. J Craniovertebr Junction Spine. 2016; 7(1): 1-3.

10. Goel A, Shah A. Reversal of longstanding musculoskeletal changes in basilar invagination after surgical decompression and stabilization. J Neurosurg Spine. 2009; 10(3):220-7.

11. Goel A, Desai K, Muzumdar DP. Atlantoaxial fixation using plate and screw method: A report of 160 treated patients. Neurosurgery. 2002; 51(6): 1351-1357.

12. Goel A, Laheri VK. Plate and screw fixation for atlantoaxial dislocation (Technical report). Acta Neurochir (Wien). 1994; 129: 47-53.

13. Goel A, Nadkarni T, Shah A, Sathe P, Patil M. Radiological evaluation of Basilar invagination without obvious atlantoaxial instability (Group B-basilar invagination): An analysis based on a study of 75 patients. World Neurosurg. 2016; 95: 375-382.

14. Goel A, Sathe P, Shah A. Atlantoaxial fixation for Basilar invagination without obvious atlantoaxial instability (Group B-basilar invagination): Outcome analysis of 63 surgically treated cases. World Neurosurg. 2017; 99: 164-170.

15. Goel A, Jain S, Shah A. Radiological evaluation of 510 cases of basilar invagination with evidence of atlantoaxial instability (Group A). World Neurosurg. In press 2017.

16. Goel A, Desai K, Bhatjiwale M, Muzumdar DP. Basilar invagination and Chiari malformation associated with cerebellar atrophy: report of two treated cases. J Clin Neurosciences. 2002; 9:194-196.

17. Goel A. Short neck, short head, short spine, and short body height - hallmarks of basilar invagination. J Craniovertebr Junction Spine 2017 Jul 1;8(3):165. DOI:10.4103/jcvjs. JCVJS_101_17. 